\title{
LIPOPEROXIDAÇÃO MUSCULAR EM RATOS TREINADOS SUBMETIDOS À RESTRIÇÃO HÍDRICA
}

\author{
Priscila Pagotto $^{1}$, Elisa Bizetti Pelai ${ }^{1}$, Roselene Modolo Regueiro Lorençoni ${ }^{2}$ \\ ${ }^{1}$ Discentes ${ }^{2}$ Docente do Departamento de Fisioterapia - FCT/UNESP - Presidente Prudente. email- \\ pripagotto@hotmail.com
}

\section{RESUMO}

O estresse oxidativo pode ser definido como o excesso de espécies reativas de oxigênios que contém um elétron não pareado na sua órbita externa, caracterizados por grande instabilidade e reatividade e está associado a vários distúrbios do organismo. O objetivo foi verificar a lipoperoxidação do músculo gastrocnêmio de ratos treinados submetidos à restrição hídrica. A amostra foi constituída por 58 ratos adultos jovens, com 90 dias, alojados em gaiolas coletivas e divididos aleatoriamente em quatro grupos, GAS, GAE, GRHS, GRHE. O programa de treinamento foi realizado em esteira rolante três vezes por semana durante 12 semanas. Nos animais sacrificados 72 horas após o treinamento, temos que a restrição hídrica apresentou diferença significativa quando comparado a todos os grupos, mostrando níveis de estresse oxidativo maiores. Concluímos que a restrição hídrica induziu um maior estresse oxidativo quando associada ao treinamento físico no músculo gastrocnêmio de ratos.

Palavras-chave: lipoperoxidação, músculo gastrocnêmio, restrição hídrica.

\section{MUSCULAR LIPOPEROXIDATION IN MICE WITH HYDRIC RESTRICTION}

\begin{abstract}
The oxidative stress can be defined as the disequilibrium between the amount of free radicals produced and the capacity antirust of the organism, associated of several disturbances of the organism. The objective of the analyse the lipoperoxidation of the gastrocnemic muscle, during the drawn out and low physical activity with hydric restriction. The sample was constituted by 58 young adult mice, with 90 days, camped in collective cages and divided in four groups, GAS, GAE, GRHS, GRHE. The training program was accomplished a week in mat three times for 12 weeks. In the animals sacrificed 72 hours after the training, we have that the restriction hídrica presented significant difference when compared her/it all the groups, showing levels of stress larger oxidativo. It was concluded that the hydric restriction induced a larger oxidative stress when associated to the physical training in the gastrocnemic muscle.

Key words: lipoperoxidation, gastrocnemic muscle, hydric restriction.
\end{abstract}




\section{INTRODUÇÃO}

Os radicais livres de oxigênio (RLO) são átomos ou moléculas altamente reativas, que contém um número ímpar de elétrons em sua última camada eletrônica, são freqüentemente produzidos em nosso organismo através de processos metabólicos oxidativos, sendo muitas vezes úteis, como na ativação do sistema imunológico ${ }^{1}$.

Estas moléculas são instáveis e procuram outras moléculas para combinar e estabilizar, retirando elétrons das biomoléculas que estão próximas (proteínas, lipídios, carboidratos e ácidos nucléicos), fazendo com que estas sofram uma modificação e possam perder a utilidade, podendo estas se tornar um radical livre ${ }^{2}$.

A atividade física pode ativar 3 principais vias de formação de radicais livres: o aumento da produção mitocondrial por ocorrer um aumento da quantidade de oxigênio consumida pelo organismo ( 2 a $5 \%$ se transforma em espécie reativa de oxigênio, em condições basais); aumento da produção citoplasmática e através da produção de RLO favorecida pelos íons ferro e cobre $^{3}$.

Durante treinamento físico intenso tem-se o aumento de 10 a 20 vezes do consumo de oxigênio total do organismo e de 100 a 200 vezes da captação do oxigênio pelo músculo, levando assim ao aumento das espécies reativas de oxigênio, portanto, as modalidades esportivas que obtém energia através do metabolismo aeróbio estão mais sujeitas a estas espécies reativas de oxigênio, com isso, os atletas ligados a essas modalidades sofrerão mais as conseqüências destas $^{4}$.

\section{OBJETIVOS}

Verificar a lipoperoxidação do músculo gastrocnêmio de ratos treinados submetidos à restrição hídrica.

\section{METODOLOGIA}

A pesquisa foi aprovada pelo CEEA (Comitê de ética na experimentação animal) da Faculdade de Medicina de São José do Rio Preto - FAMERP, com protocolo F-001-002394/2004.

Foram utilizados 58 ratos da linhagem Wistar, adultos jovens, machos, com idade de aproximadamente 90 dias. Os animais foram alojados em gaiolas de plástico, coletivas, a temperatura de $22+-3^{\circ} \mathrm{C}$, com ciclos de 12 horas de luminosidade, sendo das $7 \mathrm{~h}$ às $19 \mathrm{~h}$ (período claro) e das $19 \mathrm{~h}$ às $7 \mathrm{~h}$ (período escuro).

Os animais foram divididos aleatoriamente em quatro grupos: GAS $(n=10)$, não realizaram programa de treinamento, foram alimentados com ração padrão e água de torneira ad libitum. Forneceram a média de ingestão de água para o cálculo da restrição hídrica dos animais do GRHS. GRHS ( $n=16)$, não realizaram o programa de treinamento, sendo alimentados com ração padrão ad libitum e água de torneira fornecida de maneira controlada, com restrição de $25 \%$ a partir da média ingerida pelos animais de GAS. GAE $(n=16)$ realizaram o programa de treinamento, foram alimentados com ração padrão e água de torneira ad libitum. Forneceram a média de ingestão de água para o cálculo da restrição hídrica dos animais do GRHE. Oito animais foram sacrificados 1 hora após 0 exercício e oito após 72 horas. GRHE ( $n=16)$, realizaram o programa de treinamento, sendo alimentados com ração padrão ad libitum e água de torneira fornecida de maneira controlada, com restrição de $25 \%$ a partir da média ingerida pelos animais de GAE.

O grupo GAE foi treinado no período da manhã e o grupo GRHE no período da tarde, sempre no mesmo horário as segundas, quartas e sextas-feiras.

O programa de treinamento foi realizado em esteira rolante para animais de pequeno porte, no Laboratório de Fisiologia do Estresse da 
FCT/Unesp, durante doze semanas, sendo que a primeira semana foi de adaptação ao ambiente de treinamento.

Metade dos animais do G1, G2, G3 e G4 foram sacrificados 1 hora após a última sessão de treinamento e o restante com 72 horas após a mesma. Foi retirado o músculo gastrocnêmio e congelado em nitrogênio líquido a $-182^{\circ} \mathrm{C}$ para posterior análise de média e desvio padrão da média. A comparação entre os grupos foi realizada por meio do teste $\mathrm{T}$ de Student para dados não pareados, com valor de $p<0,05$ considerado significante.

\section{RESULTADOS}

Os valores médios dos pesos corporais dos animais dos diferentes grupos estudados no experimento se encontram na Tabela 1.

As médias do peso corporal não apresentaram diferenças estatisticamente significantes entre os grupos duas semanas antes do início do protocolo de treinamento $(p=0,67)$.
Logo após essa pesagem inicial, a restrição hídrica foi iniciada nos animais dos grupos GRHS e GRHE, e já na primeira semana de treinamento apresentaram diferença significativa com relação aos seus respectivos controles, GAS e GAE. A diferença entre o peso dos grupos aumentou após as 12 semanas de treinamento.

Tabela 1. Valores médios do peso corporal (PC) dos animais dos diferentes grupos estudados.

\begin{tabular}{llll}
\hline GRUPOS & $\begin{array}{l}\text { PC inicial (g) } \\
\text { (2 sem antes } \\
\text { do início do } \\
\text { treinamento) }\end{array}$ & $\begin{array}{l}\text { PC na 1 } \\
\text { semana de } \\
\text { treinamento } \\
(\mathrm{g})\end{array}$ & $\begin{array}{l}\mathbf{P C} \text { na 12 } \\
\text { semana de } \\
\text { treinamento } \\
(\mathrm{g})\end{array}$ \\
\hline & & & \\
GAS & $291,20 \pm 9,163$ & $371,20 \pm 11,413$ & $357,10 \pm 5,339$ \\
GRHS & $290,75 \pm 21,346$ & $311,42 \pm 2,872$ & $376,98 \pm 7,795$ \\
GAE & $294,50 \pm 11,448$ & $356,04 \pm 8,369$ & $485,33 \pm 7,163$ \\
GRHE & $287,06 \pm 19,645$ & $312,10 \pm 6,772$ & $379,29 \pm 7,399$ \\
\hline
\end{tabular}

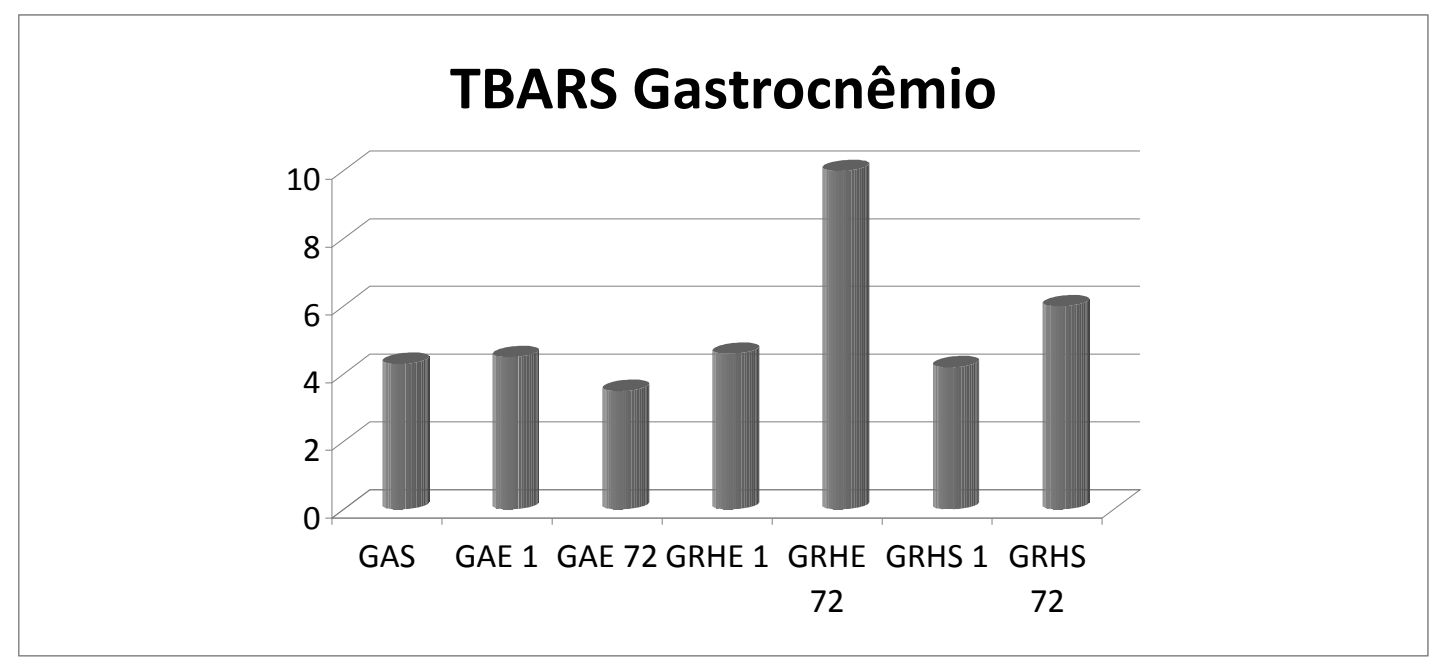

Figura 1. Mostra os resultados da lipoperoxidação nos grupos de animais sacrificados 1 hora após o término do treinamento e os sacrificados 72 horas após o mesmo.

Comparação da concentração de malonaldeído (MDA) do músculo gastrocnêmio dos diferentes grupos sacrificados 1 hora e 72 horas após a última sessão de treinamento.

\section{DISCUSSÃO}

No músculo gastrocnêmio dos animais sacrificados uma hora após o treinamento, os níveis de estresse oxidativo mostram que a restrição hídrica e o treinamento tiveram níveis 
mais altos, mas não foram significantes, entretanto o grupo GRHS mostra uma recuperação dos níveis de MDA provavelmente devido ao tempo de uma hora, que não foi suficiente para desencadear processo inflamatório e por existir apenas um fator estressante, esse músculo foi capaz de se recuperar.

Nos animais sacrificados 72 horas após o término do treinamento, temos que a restrição hídrica com o treinamento apresentou diferença significativa quando comparado a todos os grupos, mostrando níveis de estresse oxidativo maiores, onde o fator de restrição hídrica por si só, apresentou maior estresse que o fator treinamento, pois houve aumento do processo inflamatório, com menor recuperação tecidual.

A avaliação da lipoperoxidação de sistemas biológicos pelo teste de ácido tiobarbitúrico (TBARS), também denominado MDA, tem sido amplamente empregada. A quantificação de substâncias reativas ao ácido tiobarbitúrico têm sido métodos bastante utilizados para avaliar a lipoperoxidação, em variados tecidos ou amostras biológicas tais como: tecidos humanos ${ }^{4}$, músculo cardíaco de ratos $^{5,6}$, músculo gastrocnêmio de $\operatorname{ratos}^{7}$ e em exercício físico ${ }^{1}$.

Quando comparados os grupos sacrificados 1 hora após o treinamento e o de 72 horas após o treinamento, observa-se uma diferença significativa muito grande entre o grupo GRHE e o grupo GAS (controle), mostrando que o estresse do grupo que realizou o treinamento com restrição hídrica foi muito maior.

Infelizmente estudos envolvendo restrição hídrica e MDA são desconhecidos, o que impediu comparações com os resultados obtidos neste estudo.

A restrição hídrica é um fator de estresse porque com 72 horas após o sacrifício dos animais se tem aumento de processo inflamatório com uma menor recuperação de tecido.

\section{CONCLUSÃO}

Após as análises e discussão dos dados, foi observado que a restrição hídrica induziu um maior estresse oxidativo quando associada ao treinamento físico no músculo gastrocnêmio de ratos e a maior diferença se apresentou com relação ao grupo sacrificado 72 horas após o treinamento, com restrição hídrica e atividade física (GRHE), quando comparado ao grupo controle.

\section{REFERÊNCIAS}

1. Sousa TP, Oliveira PR, Pereira B. Exercício físico e estresse oxidativo: efeito do exercício físico intenso sobre a quimioluminescência urinária e malondialdeído plasmático. Revista Brasileira de Medicina do Esporte 2005;11(1):91-6.

2. Castro MAC. Estudo comparativo da produção de radicais livres e catalase nos exercícios de intensidade e duração moderadas [dissertação]. Brasília: Universidade Católica de Brasília; 2003.

3. Koury C, Donangelo, CM. Zinco, estresse oxidativo e atividade física. Revista de Nutrição 2003 out-dez;16(4):433-41.

4. Schneider CD, Oliveira AR. Radicais livres de oxigênio: mecanismos de formação e adaptação ao exercício físico. Revista Brasileira de Medicina do Esporte 2004;10(4):308-13.

5. Mastaloudis A, Leonard SW, Traber MG. Oxidative stress in athletes during extreme endurance exercise. Free Radical Biology \& Medicine $2001 \quad$ oct;31(7):911-22. http://dx.doi.org/10.1016/S0891-5849(01)00667-0

6. Burneiko RM. Influência do exercício físico no estresse oxidativo em miocárdio de ratos 
[dissertação]. Botucatu: Universidade Estadual Paulista "Julio de Mesquita Filho"; 2002.

7. Schneider CD. Avaliação do estresse oxidativo em indivíduos submetidos a diferentes intensidades de exercício em esteira rolante [dissertação]. Porto Alegre: Universidade Federal do Rio Grande do Sul; 2002. 